\title{
Spatially differentiated changes in regional climate and underlying drivers in southwestern China
}

\author{
Meng Wang ${ }^{1,2}$ • Chao Jiang ${ }^{1,2}$ • Osbert Jianxin Sun ${ }^{1,2}$
}

Received: 26 May 2021 / Accepted: 7 July 2021 / Published online: 22 July 2021

(C) The Author(s) 2021

\begin{abstract}
The climate in Southwest China are predominantly under the influences of three contrasting climate systems, namely the East Asian monsoon, the South Asian monsoon, and the westerlies. However, it is unclear if the diversified climate systems, in combination with the complex terrain and varying vegetation types, would result in contrasting patterns of changes in climate across the region. Based on the CRU TS data for the period 1901-2017, we examined the spatiotemporal characteristics of the regional climate, and identified types of climate change patterns and drivers. Overall, the region experienced significant increases in annual mean temperature during 1901-2017, with occurrence of a significant turning point in 1954 for a more pronounced warming $\left(0.16^{\circ} \mathrm{C} / 10 \mathrm{a}\right)$. The annual precipitation fluctuated greatly over the study period without apparent trend, albeit the occurrence of a significant turning point in 1928 for a slight increase in the later period $(1.19 \mathrm{~mm} / 10 \mathrm{a})$. Spatially the multi-year averages of selective climate variables during 1901-2017 displayed a trend of decreases from southeast to northwest, but with increasing variability. We
\end{abstract}

Project funding: This research was funded by Ministry

of Science and Technology of China (Grant No.

2016YFC0502104).

The online version is available at http://www.springerlink.com.

Corresponding editor: Yu Lei

Chao Jiang

jiangchao@bjfu.edu.cn

1 School of Ecology and Nature Conservation, Beijing Forestry University, Beijing 100083, People's Republic of China

2 Institute of Forestry and Climate Change Research, Beijing Forestry University, Beijing 100083,

People's Republic of China identified five major climate change types across the study region, including warmer $\left(\mathrm{T}^{+}\right)$, drier $\left(\mathrm{P}^{-}\right)$, warmer-drier $\left(\mathrm{T}^{+} \mathrm{P}^{-}\right)$, warmer-wetter $\left(\mathrm{T}^{+} \mathrm{P}^{+}\right)$, and no significant changes (NSC). The type $\mathrm{T}^{+} \mathrm{P}^{+}$mainly occurred in the western parts over the plateau sub-frigid semiarid ecozone (77.0\%) and the plateau sub-frigid semihumid ecozone (19.9\%). The central parts of the region are characterized by the type $\mathrm{T}^{+}$, corresponding to six ecozones, including the mid-subtropical humid ecozone (33.1\%), the plateau temperate humid-semihumid ecozone (28.8\%), the plateau sub-rigid semihumid ecozone (9.5\%), the southern subtropical humid ecozone (8.1\%), the plateau sub-frigid arid ecozone $(7.3 \%)$, and the plateau temperate semiarid ecozone $(6.6 \%)$. No significant change in climate was detected for the eastern parts over the mid-subtropical humid ecozone $(67.3 \%)$, the plateau temperate humid and semihumid ecozone (19.5\%) and the plateau sub-frigid semihumid ecozone (8.8\%). The types $\mathrm{P}^{-}$ and $\mathrm{T}^{+} \mathrm{P}^{-}$together accounted for less than $5 \%$ of the entire study region, which predominantly occurred in central Yunnan-Guizhou Plateau and south of the southeastern Xizang, corresponding predominantly to the mid-subtropical humid ecozone. Across the region and within the zonal climate change types, vegetation and topography both played a significant role in determining the climate variability and magnitude of changes. Our results suggest that the southwestern China experienced intensified influences of the southeasterly monsoon and the southerly monsoon in the regional climate, while the westerly alpine influences subsided; topography and vegetation affected the magnitudes of the directional changes in climate at a local scale.

Keywords Climate change - Ecozone - Regional climate · Topography $\cdot$ Vegetation 


\section{Introduction}

The southwestern China is characterized by highly complex terrains and influences of multiple climate systems. The region comprises some of the most prominent geomorphic landmarks, including the Himalaya Mountains, the Qinghai-Xizang Plateau, the Hengduan Mountains, the YunnanGuizhou Plateau and the Sichuan Basin, influenced across the region by the East Asian monsoon, the South Asian monsoon, and the westerlies. Interactions between the varying topography and influences of multiple climate systems are likely to give rise to divergent patterns of climate change across the region. Globally, the climate pattern is predominantly shaped by differential incoming radiations, imbalanced atmospheric and oceanic heat transports and the large-scale atmospheric circulations, which collectively determine the climate zonation and seasonal and inter-annual variability of temperature and precipitation. At the regional scale, geomorphology, topography and land cover are known to affect the climate patterns to some extent (Pepin et al. 2015; Bright et al. 2017; Minder et al. 2018; Aguilar-Lome et al. 2019). Many studies have shown that regions of higher elevations are more susceptible to global climate change than regions of lower elevations (Pepin et al. 2015; Li et al. 2020a, 2020b; You et al. 2020); with increases in elevation, the annual mean temperature and precipitation generally become more variable (You et al. 2020; Li et al. 2020a, 2020c; Aguilar-Lome et al. 2019; Minder et al. 2018; Pepin et al. 2015). Topography may affect climate through interference to lower atmospheric circulation and air-flow dynamics (Jiang 2003; Barros et al. 2006; Yang and Zhang 2019; He et al. 2019). Vegetation has been well recognized for playing a critical role in moderating warming effect via. alteration of albedo and evapotranspiration worldwide (Peng et al. 2014; Shen et al. 2015; Bright et al. 2017; Zeng et al. 2017; Huang et al. 2020; Li et al. 2020c).

The rising of Himalaya Mountains has produced a profound impact on the regional climate as well as topography in southwestern China. Climatically, Himalaya Mountains completely blocks the forcing of warmer and moist Indian Ocean monsoon, replaced by heavy influences of the sinking cold draught resulting from glaciers and permanent snow-covers. The topography features a declining elevation from more than $5500 \mathrm{~m}$ asl in the west to below $1000 \mathrm{~m}$ asl in the east and southeast, with elevational differences of several thousands in magnitude (Fig. 1a). Associated with the variable topography and influences of multiple climate systems are diversified landscape matrices and changes in vegetation cover and types across the region (Fig. 1b). Occurrence of these special features make the southwestern China an highly interesting case study on local controls of climate change, especially for examining the differentiated patterns of climate change as affected interactively by regionally prevailing climate systems, topography and vegetation.
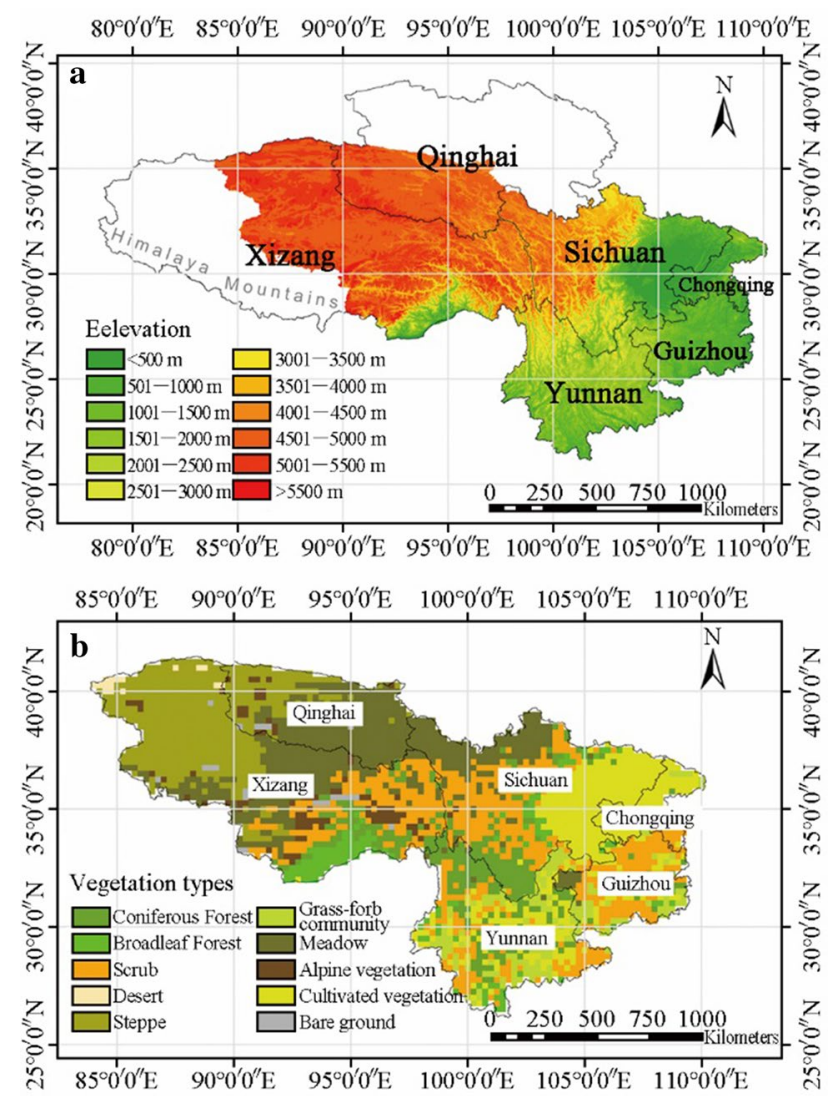

Fig. 1 Overview of a topography and $\mathbf{b}$ vegetation cover types in part of southwestern China. The clear space in panel a are areas within the respective provincial territory not included in this study

In this study, we were interested to know: (a) what are the general patterns of climate change in southwestern China over the past 100 years; and (b) how the topography and vegetation would be related to the contrasting patterns of climate change. Based on monthly high-resolution gridded time-series dataset CRU TS4.02 (Climatic Research Unit, University of East Anglia, UK), and the regional data on topography and vegetation, we identified typical patterns of climate change and the magnitude of changes across the study region in southwestern China, and analyzed the inter-relationships of the climate change types and the magnitudes of changes with topography and vegetation by means of data synthesis and interrogative statistical analysis.

\section{Materials and methods}

\section{Study region}

The administrative context of the Southwest China consists of four provinces and one province-level municipality, including Sichuan, Guizhou, Yunnan, Xizang, and 
Chongqing. In this study, we subjectively used the term "southwestern China" with a broader geographical implication and consideration of vegetation and landscape settings, covering Sichuan, Chongqin, Guizhou, and Yunnan in the entirety, and parts of Xizang and Qinghai (areas with relief information in Fig. 1a). The whole study region lies between $21.14^{\circ}$ and $36.48^{\circ} \mathrm{N}$ in latitude, and from $83.87^{\circ}$ to $110.19^{\circ} \mathrm{E}$ in longitude, with a total area of $2.09 \times 10^{6} \mathrm{~km}^{2}$. Geomorphically, the region is featured with the landmarks of the Qinghai-Xizang Plateau, the Hengduan Mountains, the Sichuan Basin, and the Yunnan-Guizhou Plateau, with topography exhibiting a pattern of declining elevation from west and northwest to east and southeast.

\section{Data sources and processing}

Data on topography, climate, vegetation and ecozone distributions were obtained for the study region from publically available sources. Secondary data processing was performed for scale consistency and to meet the requirement of this study either by resampling or rescaling.

The DEM data for the study region were downloaded from the internet archive of the Resources and Environmental Science and Data Center of Institute of Geographic Sciences and Natural Resources, the Chinese Academy of Sciences (https://www.resdc.cn/data.aspx?DATAID=123). The original data at $1 \mathrm{~km}$ spatial resolution were up-scaled to $0.25^{\circ} \times 0.25^{\circ}$ based on bilinear extrapolation in ArcGIS10.6 The aspect and slope were derived from the $1 \mathrm{~km}$ DEM data using the procedures under Spatial Analyst in ArcGIS10.6. The slope was categorized into: $0-45^{\circ}, 45^{\circ}-90^{\circ}$, $90^{\circ}-135^{\circ}, 135^{\circ}-180^{\circ}, 180^{\circ}-225^{\circ}, 225^{\circ}-270^{\circ}, 270^{\circ}-315^{\circ}$, and $315^{\circ}-360^{\circ}$, facing eight directions in equal angles. We also derived the relief amplitude from the $1 \mathrm{~km}$ resolution DEM using the Phython Module in the ArcGIS10.6 environment. The specific computational steps were as follows: first, the study region was sequentially divided into grid window sizes of $2 \times 2,3 \times 3,4 \times 4, \ldots$, and $50 \times 50$, the difference between the maximum and minimum DEM was calculated for each grid and the values were averaged across all grids of the same window sizes. A response curve of average differential DEM values vs. grid window sizes was then drawn, and the window size corresponding to the maximum differential DEM value was considered the appropriate area for expressing the relief amplitude across the study region; in this study, the optimal window size was determined to be $16 \times 16 \mathrm{~km}$, or $256 \mathrm{~km}^{-2}$.

The CRU TS (Climatic Research Unit gridded Time Series) dataset v.4.02 were used for extracting the monthly temperature and precipitation of the study region at a spatial resolution of $0.5^{\circ} \times 0.5^{\circ}$ for the period $1901-2017$. The CRU TS v4.02 were downloaded from the internet archive of the Climate Research Unit, University of Anglia, UK (https://crudata.uea.ac.uk/cru/data/hrg/). The CRU TS v.4 datasets were developed by Harris et al. (2020) by interpolating monthly climate anomalies from extensive networks of weather station observations worldwide. They are frequently used as reliable climate data sources for studying global or regional patterns of climate change and impacts on ecosystems (e.g. Buermann et al. 2018; Bromley et al. 2020; Li et al. 2020b; Tan et al. 2020). In this study, the monthly values of CRU TS v.4.02 were converted to annual average for temperature and annual total for precipitation, and then down-scaled to $0.25^{\circ} \times 0.25^{\circ}$ from $0.5^{\circ} \times 0.5^{\circ}$ spatial resolution using the cubic spline interpolation method (Knott 2012 ), incorporating the DEM information at $0.25^{\circ} \times 0.25^{\circ}$ spatial resolution.

The digitized $1: 1,000,000$ vegetation maps based on the Vegetation Atlas of China (The Editorial Committee of Vegetation Map of China 2007) was used for extracting information on the regional vegetation types and their distributions. The original dataset was converted to gridded data at $0.25^{\circ} \times 0.25^{\circ}$ spatial resolution using ArcGIS10.6. The scattered and minor vegetation patches were aggregated into predominant vegetation types prevailing in local areas, and the regional vegetation/landcover types were aggregated into ten major groups consisting of coniferous forest, broadleaf forest, scrub, desert, steppe, grass-for community, meadow, alpine vegetation, cultivated vegetation, and bare ground (Fig. 1b).

The GIMMS (global inventory monitoring and modeling studies) NDVI data are commonly used to study large scale spatiotemporal dynamics of vegetation (Ruffin et al. 2008; Buermann et al. 2018; Yin et al. 2020). In this study, we used the GIMMS NDVI derived from AVHRR remote sensing imagery covering the period January 1982-December 2015, with temporal step of $15 \mathrm{~d}$ and spatial resolution of $8 \times 8 \mathrm{~km}$ (https://ecocast.arc.nasa.gov/data/pub/gimms/). The original dataset was subjected to geometric calibration and corrections for radiation and atmospheric conditions. However, due to the high frequency of cloudy and rainy days in our study region, we further performed Savitzky-Golay filtering on the 24-period NDVI to develop new NDVI time series (Ruffin et al. 2008; Yin et al. 2020), hence eliminating the interference of clouds and rainy weather conditions. The monthly maximum NDVI were computed and used for calculating multi-year average NDVI. The computations followed the steps of:

$\mathrm{NDVI}_{m i}=\operatorname{Max}\left(\mathrm{NDVI}_{m i j}\right)$

$\overline{\mathrm{NDVI}_{m}}=\frac{\sum_{1}^{12} \mathrm{NDVI}_{m i}}{12}$ 
$\overline{\mathrm{NDVI}}=\frac{\sum_{1}^{m} \overline{\mathrm{NDVI}_{m}}}{m}$

where, NDVI $m i$ represents the NDVI of the $i$-th month in the $m$-th year $(i=1,2, \ldots, 12, m=1,2, \ldots, 34)$, and $\mathrm{NDVI}_{m i j}$ refers to the NDVI of the $j$-th 15 th day of the $i$-th month in the $m$-th year data $(j=1,2), \overline{\mathrm{NDVI}_{m}}$ refers to the average value of NDVI in the $m$-th year, $\overline{\text { NDVI }}$ refers to the multiyear average NDVI.

The multi-year average NDVI was resampled to a spatial resolution of $0.25^{\circ} \times 0.25^{\circ}$ to match with the climate data.

Based on the definition and classifications of Zheng (2008), the study region covers eight categories of ecozones: I, mid-subtropical humid ecozone; II, southern subtropical humid ecozone; III, marginal tropical humid ecozone; IV, plateau sub-frigid semihumid ecozone; $\mathrm{V}$, plateau sub-frigid semiarid ecozone; VI, plateau sub-frigid arid ecozone; VII, plateau temperate humid-semihumid ecozone; VIII, plateau temperate semiarid ecozone. We obtained the vector values on the distributions of these ecozones from the Resource and Environmental Science and Data Center of Institute of Geographic Sciences and Natural Resources, the Chinese Academy of Sciences (http://www.resdc.cn/data.aspx).

\section{Data analysis}

Trend detection was performed on the temporal dynamics of annual average temperature and annual precipitation. The least-square method was used to calculate the trend of changes in annual temperature and annual precipitation, with the slope of the fitting equation indicating the rate of changes, which was calculated as (Li and Yang 2017):

slope $=\frac{n \sum_{i=1}^{n} i x_{i}-\sum_{i=1}^{n} i \sum_{i=1}^{n} x_{i}}{n \sum_{i=1}^{n} i^{2}-\left(\sum_{i=1}^{n} i\right)^{2}}$

where, $n$ is the length of the study period, i.e. from 1901 to 2017 for a total of 117 years; $x_{i}$ is the annual average temperature or annual precipitation of the $i$-th year $(i=1,2, \ldots$, 117). The value of slope $>0$ means that the climate during the study period has a trend of warming or humidification; otherwise, it has a trend of cooling or drying. The significance level was determined by $t$-test. The types of climate change were then categorized and analyzed for correlations and associations with geographic, topographic and vegetation factors.

Using piecewise linear regression, the two periods before and after the turning point must be greater than or equal to ten years. The sum of the squared residuals of the two sections before and after the turning point was calculated with
$1910,1911, \ldots, 2008$, and the square of the fitted residual of the year when the sum reached the minimum value was considered the optimal solution of the fitting, which is defined as the turning point as in Wang et al. (2010). F-test was performed to determine the significance level of the turning point.

Multiple regression analysis was used to identify the key controlling factors and their relative importance in explaining the variations in climate change patterns, following the method described in Gross et al. (2017). We established multiple regression models of the climate change types as function of topography, vegetation, and their interactions. The topographic variables included elevation, aspect and slope, and relief amplitude; the effect of vegetation was represented by vegetation type and NDVI. Akaike Information Criterion (AIC) was used to select the best fitting models and predictors of spatial climate change patterns in terms of direction and magnitude. The relative importance of the predictors was evaluated by the relative effect of the parameter estimates for each of the predictors compared to the effect of all parameter estimates in a given model.

Pearson correlation analysis was performed to determine the inter-relationships of changes in annual average temperature $(\Delta T \mathrm{a})$ and annual precipitation $(\Delta P \mathrm{r})$ with selective topographic and vegetation variables within each climate change type.

All data analysis, unless otherwise specified, were performed using $R$-package (R Development Core team 2018).

\section{Results}

\section{Temporal variations of temperature and precipitation}

During the period of $1901-2017$, the mean annual temperature was $5.76{ }^{\circ} \mathrm{C}$ with a highly significant trend of increases as a whole $\left(0.05^{\circ} \mathrm{C} / 10 \mathrm{a}, P<0.01\right)$. A significant turning point for annual average temperature occurred in 1954 $\left(F>F_{0.05}\right)$; the trend of temperature increases was highly significant before $1954(P<0.01$; Fig. 2a), with an increase in temperature by $0.70{ }^{\circ} \mathrm{C}$ in 54 years. After 1954 , the rate of temperature increases was even greater, reaching as high as $0.16^{\circ} \mathrm{C} / 10 \mathrm{a}(P<0.01)$, which was about 3.44 times of that for the entire period. The mean annual precipitation during $1901-2017$ was $768.4 \mathrm{~mm}$, fluctuating greatly without significant trend of changes $(P>0.05$; Fig. $2 b)$. A significant turning point for precipitation occurred in $1928\left(F>F_{0.05}\right)$. Before 1928, the annual precipitation increased significantly $(P<0.05)$, by $54.8 \mathrm{~mm}$ in 28 years; whereas after 1928 , no clear trend was identifiable in annual precipitation (Fig. 2b). 
Fig. 2 Trend of changes in a annual average temperature $\left(T_{\mathrm{a}}\right)$, and $\mathbf{b}$ annual precipitation $\left(P_{\mathrm{r}}\right)$ from 1901 to 2017 from 1901 to 2017 over the study region in southwestern China

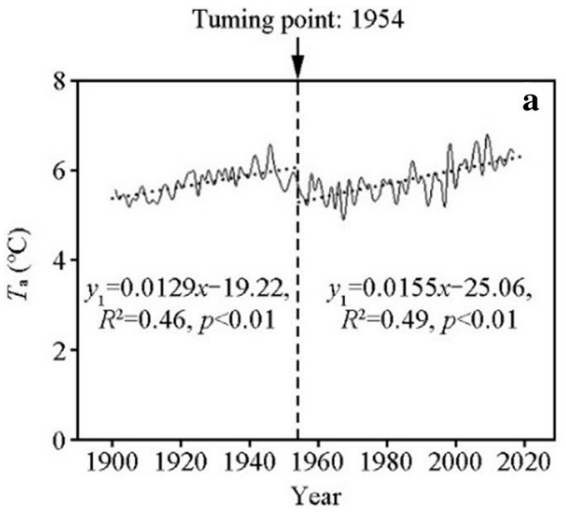

\section{Spatial variations in temperature and precipitation}

The mean annual temperature (MAT) during 1901-2017 displayed a trend of gradual decline from southeast to northwest of the study region. The difference between the maximum and minimum values was as high as $32.9^{\circ} \mathrm{C}$ (Fig. 3a). About $38.3 \%$ of the region had sub-zero mean annual temperatures, occurring mainly in the northwest. The spatial variations in mean annual precipitation (MAP) were similar to that of MAT; the maximum and minimum annual precipitation differed by about $1941.5 \mathrm{~mm}$ (Fig. 3b).

The rate of change in the annual average temperature becomes more apparent from southeast to northwest (Fig. 3c), with a range from -0.01 to $0.11^{\circ} \mathrm{C} / 10 \mathrm{a}$ and an average rate at $0.04^{\circ} \mathrm{C} / 10 \mathrm{a}$. About $74.1 \%$ of the study region showed a significant trend of temperature increases, whilst $85^{\circ} 0^{\prime} 0^{\prime \prime} \mathrm{E} \quad 90^{\circ} 0^{\prime} 0^{\prime \prime} \mathrm{E} \quad 95^{\circ} 0^{\prime} 0^{\prime \prime} \mathrm{E} \quad 100^{\circ} 0^{\prime} 0^{\prime \prime} \mathrm{E} \quad 105^{\circ} 0^{\prime} 0^{\prime \prime} \mathrm{E} \quad 110^{\circ} 0^{\prime} 0^{\prime \prime} \mathrm{E}$

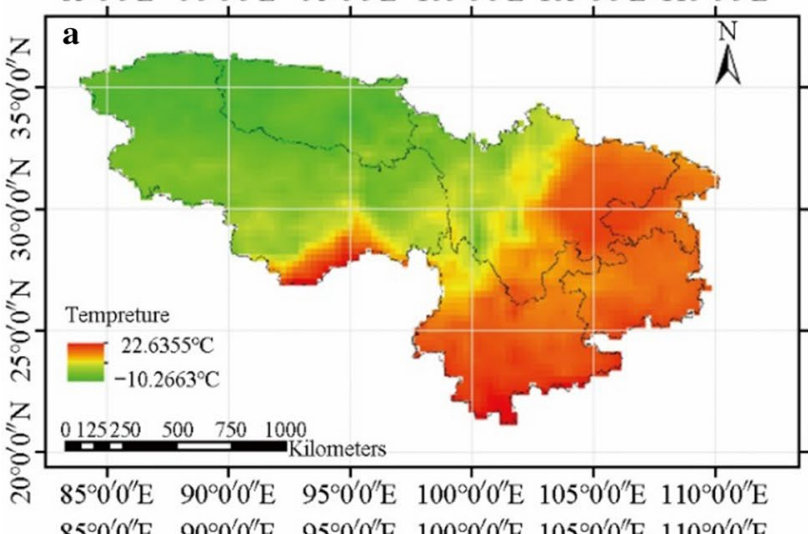

$85^{\circ} 0^{\prime} 0^{\prime \prime} \mathrm{E} \quad 90^{\circ} 0^{\prime} 0^{\prime \prime} \mathrm{E} \quad 95^{\circ} 0^{\prime} 0^{\prime \prime} \mathrm{E} \quad 100^{\circ} 0^{\prime} 0^{\prime \prime} \mathrm{E} \quad 105^{\circ} 0^{\prime} 0^{\prime \prime} \mathrm{E} \quad 110^{\circ} 0^{\prime} 0^{\prime \prime} \mathrm{E}$

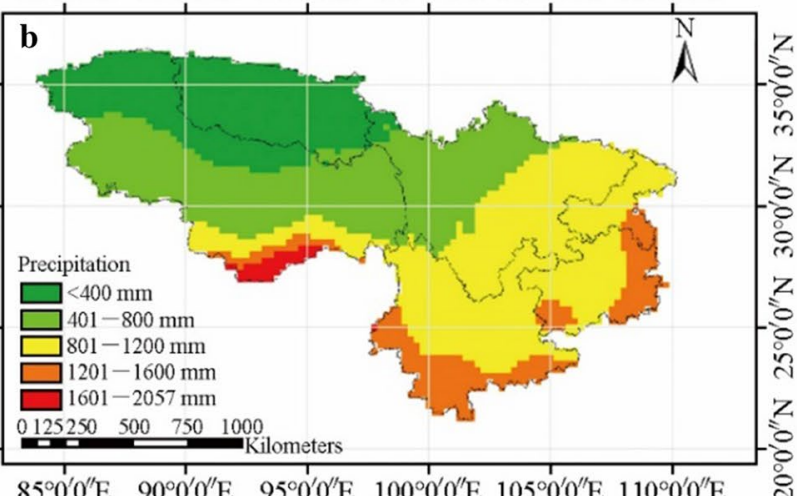

$85^{\circ} 0^{\prime} 0^{\prime \prime} \mathrm{E} \quad 90^{\circ} 0^{\prime} 0^{\prime \prime} \mathrm{E} \quad 95^{\circ} 0^{\prime} 0^{\prime \prime} \mathrm{E} \quad 100^{\circ} 0^{\prime} 0^{\prime \prime} \mathrm{E} \quad 105^{\circ} 0^{\prime} 0^{\prime \prime} \mathrm{E} \quad 110^{\circ} 0^{\prime} 0^{\prime \prime} \mathrm{E}$

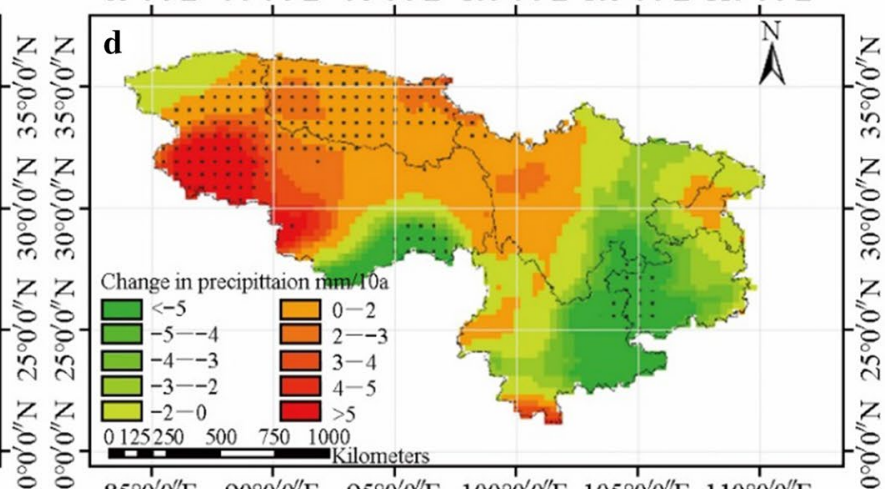

Fig. 3 Spatial patterns in a mean annual temperature (MAT), b mean annual precipitation (MAP), $\mathbf{c}$ decadal rate of changes in MAT, and d decadal rate of changes in MAP, during 1901-2017 in the study region of southwestern China. The grey dots on Panels $\mathbf{c}$ and $\mathbf{d}$ mark the areas with significant changes in the trend $(P<0.05)$ 
about a quarter of the region remained relatively neutral in temperature changes, mainly in western Sichuan Basin and the central-eastern Yunnan-Guizhou Plateau. In the eastern part of the Yunnan-Guizhou Plateau, there was a trend of cooling over a narrow space, accounting for only $1.9 \%$ of the study region. The rate of changes in annual precipitation (Fig. 3d) spatially varied from -12.8 to $7.09 \mathrm{~mm} / 10 \mathrm{a}$, with an average rate of $-0.48 \mathrm{~mm} / 10 \mathrm{a}$. About half of the study region, mainly in the west, were found to have increased annual precipitation, but the increases were only significant $(P<0.05)$ over $26 \%$ of the total region, corresponding to topography of plateau, high mountains and valleys (Fig. 3d).

\section{Types of climate change}

Across the study region, we identified five major climate change types, including warmer $\left(\mathrm{T}^{+}\right)$, drier $\left(\mathrm{P}^{-}\right)$, warmerdrier $\left(\mathrm{T}^{+} \mathrm{P}^{-}\right)$, warmer-wetter $\left(\mathrm{T}^{+} \mathrm{P}^{+}\right)$, and no significant changes (NSC), with distinct spatial distributions (Fig. 4a). In terms of the spatial coverage, about half of the region were of the type $\mathrm{T}^{+}, 22 \%$ the type $\mathrm{T}^{+} \mathrm{P}^{+}, 2.6 \%$ the type $\mathrm{P}^{-}$, and $1.6 \%$ the type $\mathrm{T}^{+} \mathrm{P}^{-} ; 23 \%$ of the region were not detected with a clear pattern of climate change.

Spatially, the climate change type $\mathrm{T}^{+} \mathrm{P}^{+}$mainly occurred in the western parts over the plateau sub-frigid semiarid ecozone $(77.0 \%)$ and the plateau sub-frigid semihumid ecozone (19.9\%) (Fig. 4a, b). The central parts of the region are characterized by the type $\mathrm{T}^{+}$, corresponding to six ecozones, including the mid-subtropical humid ecozone (33.1\%), the plateau temperate humid-semihumid ecozone (28.8\%), the plateau sub-rigid semihumid ecozone (9.5\%), the southern subtropical humid ecozone (8.1\%), the plateau sub-frigid arid ecozone (7.3\%), and the plateau temperate semiarid ecozone (6.6\%). No significant change in climate was detected for the eastern areas over the mid-subtropical humid ecozone $(67.3 \%)$, the plateau temperate humid and semihumid ecozone (19.5\%) and the plateau sub-frigid semihumid ecozone (8.8\%). The climate change types $\mathrm{T}^{+} \mathrm{P}^{-}$and $\mathrm{P}^{-}$were confined to the south of the southeastern Xizang and central Yunnan-Guizhou plateau, respectively, with the type $\mathrm{T}^{+} \mathrm{P}^{-}$made up $88 \%$ of the mid-subtropical humid ecozone and more than $10 \%$ of the plateau temperate humidsemihumid ecozone, and the type $\mathrm{P}^{-}$exclusively in the midsubtropical humid ecozone (Fig. 4b).

\section{Influences of topography and vegetation on climate}

The NDVI declined from the east to the west of study region along with increasing elevations (Fig. 5a); the vegetation types displayed patchy but a broad zonal pattern, changing from mostly mosaics of scrubs, cultivated plants, grassforb communities, coniferous and broadleaf forests in the east and middle parts of the study region, to predominantly
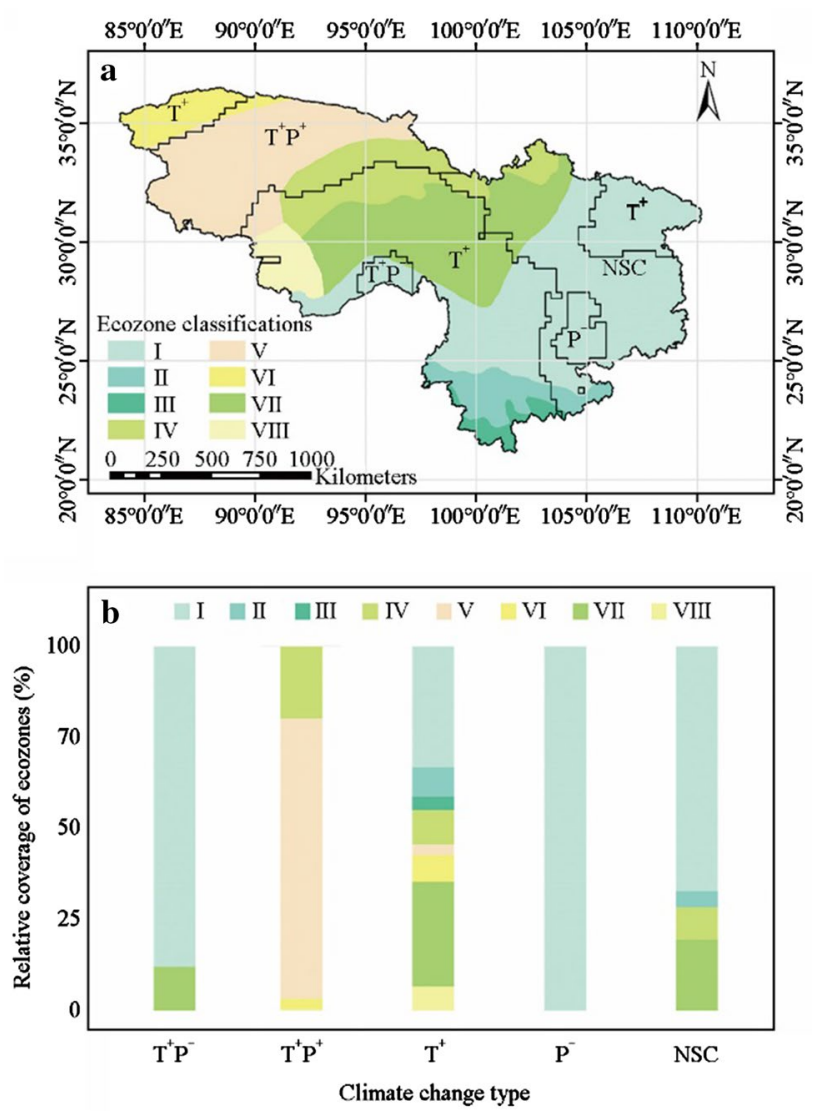

Fig. 4 a Spatial distributions of climate change types and ecozone classifications, and $\mathbf{b}$ the distribution of ecozone classifications within climate change types in the study region of southwestern China. Classification of climate change types: $\mathrm{T}^{+}$, warmer; $\mathrm{P}^{-}$, drier; $\mathrm{T}^{+} \mathrm{P}^{-}$, warmer-drier; $\mathrm{T}^{+} \mathrm{P}^{+}$, warmer-wetter; NSC, no significant change. Ecozone classifications: I, mid-subtropical humid ecozone; II, southern subtropical humid ecozone; III, marginal tropical humid eozone; IV, plateau sub-frigid semihumid ecozone; V, plateau sub-frigid semiarid ecozone; VI, plateau sub-frigid arid ecozone; VII, plateau temperate humid-semihumid eozone; VIII, plateau temperate semiarid ecozone

alpine meadow and steppe for majority of the western areas (Fig. 5b).

At the regional scale, the land surface conditions explained $72.6 \%$ of variations in temperature changes and $53 \%$ of variations in precipitation changes, respectively (both at $P<0.01$; Tables 1 and 2). Vegetation, topography and their interactions had about the equal contributions in explaining the variance in temperature changes (Table 1); whereas the variance in precipitation changes was predominantly explainable by topography, followed by an interaction between vegetation and topography (Table 2). Amongst the vegetation and topographic variables and their interactions, NDVI, elevation and their interaction prevailed as the three top predictors for changes in both temperature and precipitation (Tables 1 and 2). 


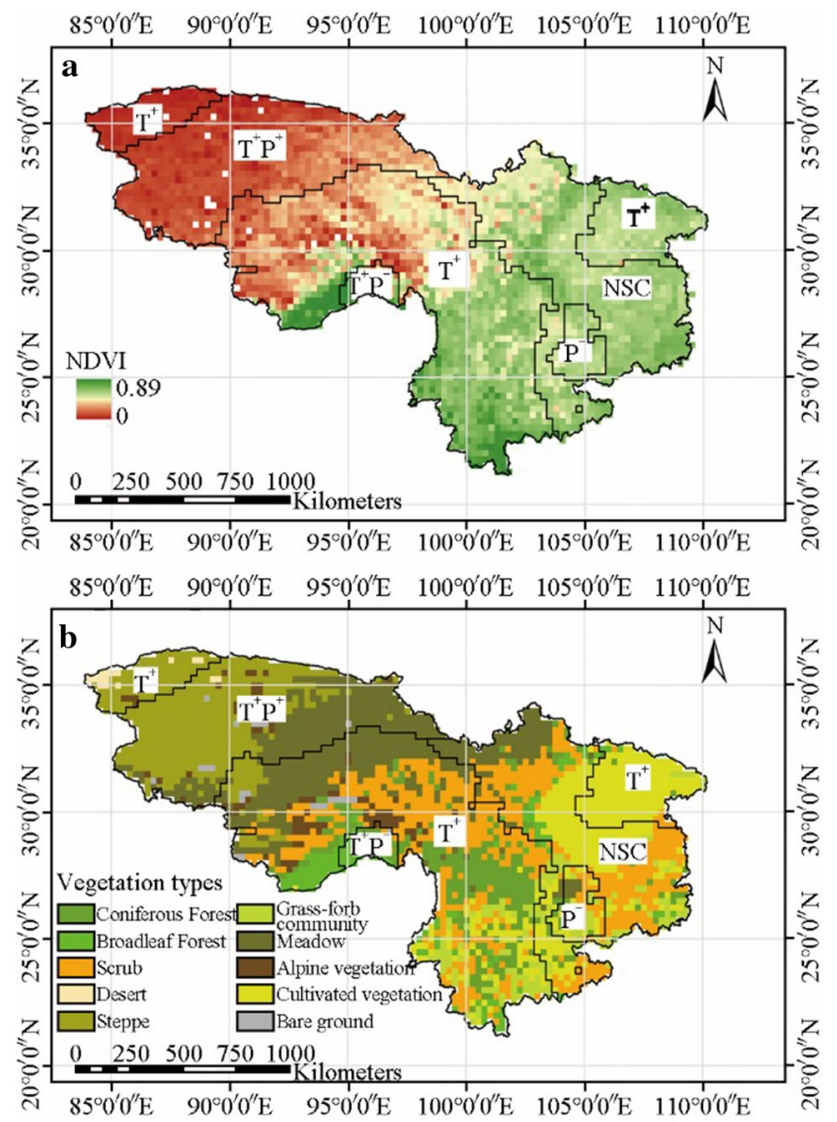

Fig. 5 Spatial associations of climate change types with a normalized difference vegetation index (NDVI), and $\mathbf{b}$ vegetation types in the study region of southwestern China. Climate change types: $\mathrm{T}^{+}$, warmer; $\mathrm{P}^{-}$drier; $\mathrm{T}^{+} \mathrm{P}^{-}$, warmer-drier; $\mathrm{T}^{+} \mathrm{P}^{+}$, warmer-wetter; NSC, no significant change

When stratified by climate change types, the land surface conditions had highly significant $(P<0.01)$ contributions to temperature changes in predominantly the types $\mathrm{T}^{+} \mathrm{P}^{-}, \mathrm{T}^{+} \mathrm{P}^{+}$, and $\mathrm{T}^{+}$(Table 1$)$. In the type $\mathrm{T}^{+} \mathrm{P}^{-}$, NDVI was a highly significant $(P<0.01)$ and the most important predictor of temperature changes; in the type $\mathrm{T}^{+} \mathrm{P}^{+}$, the top three highly significant $(P<0.01)$ predictors were NDVI, elevation, and vegetation type; whereas in the type $\mathrm{T}^{+}$, interactions between NDVI and elevation and between NDVI and relief amplitude as well as individual effects of elevation and NDVI had the most influential contributions to the variations in temperature changes (Table 1). On precipitation changes, highly significant effects $(P<0.01)$ of the land surface conditions were only found in the climate changes types $\mathrm{T}^{+} \mathrm{P}^{+}, \mathrm{T}^{+}$and NSC; the highly significant $(P<0.01)$ and most prominent predictors were relief amplitude, vegetation type and an interaction between NDVI and elevation in the type $\mathrm{T}^{+} \mathrm{P}^{+}$; elevation, NDVI and an interaction between NDVI and elevation in the type $\mathrm{T}^{+}$; and elevation and relief amplitude in the type NSC (Table 2). Due largely to the spatial confinement and only local occurrence, modelling the relative contributions of vegetation and topographic variables for predicting precipitation changes were not successful for the climate change types $\mathrm{T}^{+} \mathrm{P}^{-}$and $\mathrm{P}^{-}$(Fig. 4a).

The Pearson correlation analysis shows that, at the regional scale, the changes in both annual average temperature $(\Delta T \mathrm{a})$ and annual precipitation $(\Delta P \mathrm{Pr})$ had highly significant $(P<0.01)$ positive correlations with elevation, and highly significant $(P<0.01)$ negative correlations with NDVI (Table 3 ). The positive correlations between $\Delta T \mathrm{a}$ and elevation mainly occurred for the climate change types $\mathrm{T}^{+} \mathrm{P}^{+}, \mathrm{T}^{+}$, and $\mathrm{P}^{-}$; whereas the negative correlations between $\Delta T$ a and NDVI were predominantly found in the $\mathrm{T}^{+} \mathrm{P}^{+}$and $\mathrm{T}^{+}$. Intriguingly, the correlations of $\Delta T \mathrm{a}$ with elevation and NDVI were in reversal orders from the general patterns in the type $\mathrm{T}^{+} \mathrm{P}^{-}$. The positive correlations between $\Delta P \mathrm{r}$ and elevation were prominent in the climate change types $\mathrm{T}^{+} \mathrm{P}^{-}$, $\mathrm{T}^{+}$, and NSC; whereas, the negative correlations between $\Delta P r$ and NDVI were predominantly featured in the types $\mathrm{T}^{+} \mathrm{P}^{-}$and $\mathrm{T}^{+}$(Table 3).

\section{Discussion}

Examination of the historical climate data revealed that the temperature in southwestern China has trended significantly higher for nearly 120 years since 1901 . A significant turning point occurred in 1954, after which time the rate of temperature increases greatly accelerated to the level of $0.16^{\circ} \mathrm{C} 10 \mathrm{a}$. This rate was 3.44 times of the average rate for the entire period during 1901-2017. This pattern of temperature changes for southwestern China is in line with findings for the Qinghai-Xizang Plateau from previous studies (Kang et al. 2010). Several studies have demonstrated that the temperature in the Qinghai-Xizang Plateau started rising from 1960s, with rate of change above the national average (Cai et al. 2003; Piao et al. 2010; China Meteorological Administration 2020). A significant turning point for precipitation occurred in 1928 in the region, separating a pattern of significant increasing trend prior to 1928 and a pattern of greater inter-annual fluctuations without a significant trend of temporal changes after 1928. Previous studies by Li et al. (2010) and Duan et al. (2020) indicated that the precipitation in the Qinghai-Xizang Plateau displayed a trend of gradual increases since the 1960s. This pattern of increasing precipitation was not found at the regional scale in southwestern China in this study.

The MAT and MAP for the period of 1901-2017 both displayed a pattern of gradual decline from the southeast to the northwest of the southwestern China, corresponding to increasing intensity of changes. Overall, the areas west of the longitude $98^{\circ} \mathrm{E}$ and north of the latitude $30^{\circ} \mathrm{N}$ experienced warmer and wetter trend of climate changes. This is 
Table 1 Summary of variance fractions in temperature changes explainable by selective vegetation and topographic variables for different categories of climate change type

\begin{tabular}{|c|c|c|c|c|c|c|c|}
\hline Factor type & Variable & Regional average & $\mathrm{T}^{+} \mathrm{P}^{-}$ & $\mathrm{T}^{+} \mathrm{P}^{+}$ & $\mathrm{T}^{+}$ & $\mathrm{P}^{-}$ & NSC \\
\hline \multirow[t]{5}{*}{ Vegetation } & Vegetation type (quadratic) & $4.48 * *$ & $2.74^{\mathrm{NS}}$ & $0.49^{\mathrm{NS}}$ & $0.01^{\mathrm{NS}}$ & $23.4 *$ & $9.73 * *$ \\
\hline & Vegetation type (linear) & $0.57^{\mathrm{NS}}$ & $5.93^{\mathrm{NS}}$ & $13.2 * *$ & $3.58 * *$ & $6.93^{\mathrm{NS}}$ & $11.6 * *$ \\
\hline & NDVI (quadratic) & $6.15^{* *}$ & 1.17 & $2.7^{*}$ & $1.16^{\mathrm{NS}}$ & $5.01^{\mathrm{NS}}$ & $2.98^{\mathrm{NS}}$ \\
\hline & NDVI (linear) & $17.6^{* *}$ & $32.6 * *$ & $25.9 * *$ & $11.2 * *$ & $3.54^{\mathrm{NS}}$ & $26.1 * *$ \\
\hline & Subtotal & 28.8 & 42.4 & 42.3 & 15.9 & 38.9 & 50.4 \\
\hline \multirow[t]{9}{*}{ Topography } & Aspect (quadratic) & - & $2.59^{\mathrm{NS}}$ & $0.86^{\mathrm{NS}}$ & $0.04^{\mathrm{NS}}$ & - & $0.13^{\mathrm{NS}}$ \\
\hline & Aspect (linear) & $0.04^{\mathrm{NS}}$ & $2.12^{\mathrm{NS}}$ & $2.55^{\mathrm{NS}}$ & $0.06^{\mathrm{NS}}$ & - & $1.05^{\mathrm{NS}}$ \\
\hline & Relief amplitude (quadratic) & $3.49 * *$ & $0.06^{\mathrm{NS}}$ & $0.02^{\mathrm{NS}}$ & $0.32^{\mathrm{NS}}$ & $5.01^{\mathrm{NS}}$ & $4.08 *$ \\
\hline & Relief amplitude (linear) & $4.21 * *$ & $4.63^{\mathrm{NS}}$ & $4.49 *$ & $3.45^{*}$ & $8.21^{\mathrm{NS}}$ & $12.9 * *$ \\
\hline & Slope (quadratic) & $0.63^{\mathrm{NS}}$ & - & $4.44 * *$ & $0.40^{\mathrm{NS}}$ & - & $0.14^{\mathrm{NS}}$ \\
\hline & Slope (linear) & $2.07^{\mathrm{NS}}$ & $3.51^{\mathrm{NS}}$ & $6.81 * *$ & $0.38^{\mathrm{NS}}$ & - & $0.23^{\mathrm{NS}}$ \\
\hline & Elevation (quadratic) & $0.02^{\mathrm{NS}}$ & $2.28^{\mathrm{NS}}$ & $2.47 *$ & $8.13 * *$ & $1.41^{\mathrm{NS}}$ & $6.36^{\mathrm{NS}}$ \\
\hline & Elevation (linear) & $21.1 * *$ & $8.97^{\mathrm{NS}}$ & $15.8 * *$ & $18.1 * *$ & $29.1 * *$ & $1.11^{\mathrm{NS}}$ \\
\hline & Subtotal & 31.6 & 24.2 & 37.5 & 30.9 & 43.7 & 26.1 \\
\hline \multirow[t]{9}{*}{ Interactions } & NDVI elevation & $20.6^{* *}$ & $16.8^{\mathrm{NS}}$ & $4.40^{*}$ & $33.8^{* *}$ & $5.38^{\mathrm{NS}}$ & $5.62^{\mathrm{NS}}$ \\
\hline & NDVI slope & $0.09^{\mathrm{NS}}$ & $0.18^{\mathrm{NS}}$ & $4.63^{*}$ & - & - & - \\
\hline & NDVI relief amplitude & $13.0 * *$ & $1.67^{\mathrm{NS}}$ & $3.93 *$ & $18.8 * *$ & $11.3^{\mathrm{NS}}$ & $10.5^{* *}$ \\
\hline & NDVI aspect & $0.05^{\mathrm{NS}}$ & - & $0.34^{\mathrm{NS}}$ & - & - & $2.06^{\mathrm{NS}}$ \\
\hline & Vegetation type aspect & $1.37 * *$ & $0.54^{\mathrm{NS}}$ & $0.21^{\mathrm{NS}}$ & $0.50^{\mathrm{NS}}$ & - & $0.02^{\mathrm{NS}}$ \\
\hline & Vegetation type slope & $0.02^{\mathrm{NS}}$ & - & $0.17^{\mathrm{NS}}$ & - & - & - \\
\hline & Vegetation type relief amplitude & $0.05^{\mathrm{NS}}$ & - & $0.53^{\mathrm{NS}}$ & $0.04^{\mathrm{NS}}$ & - & $0.21^{\mathrm{NS}}$ \\
\hline & Vegetation type elevation & $4.47 * *$ & 14.2 & $5.99 * *$ & - & $0.68^{\mathrm{NS}}$ & $5.15^{\mathrm{NS}}$ \\
\hline & Subtotal & 39.7 & 33.4 & 20.2 & 53.2 & 17.7 & 23.5 \\
\hline Adj $r^{2}$ & $72.6^{* *}$ & $61.1 * *$ & $66.6^{* *}$ & $59.2 * *$ & $24.9 * *$ & $22.4 * *$ & \\
\hline
\end{tabular}

*Significant at $P<0.05 ; * *$ significant at $P<0.01 ;{ }^{\text {NS }}$ not significant

The missing values are due to insignificant contributions of the respective factors. Classification of climate change types: $\mathrm{T}^{+}$, warmer; $\mathrm{P}^{-}$, drier; $\mathrm{T}^{+} \mathrm{P}^{-}$, warmer-drier; $\mathrm{T}^{+} \mathrm{P}^{+}$, warmer-wetter; NSC, no significant change

mostly consistent with findings based on observations from the local meteorological stations in the Qinghai and Xizang territory (Liu et al. 2009; Liu and Chen 2000; Yang et al. 2011; Chen et al. 2015; IPCC 2013; China Meteorological Administration 2020; Zhao et al. 2020). The central parts of southwestern China are mainly featured with warming, whereas in the east the climate remained largely unchanged. The climate in the western areas of southwestern China is mainly under influence of westerlies and is characterized by increased intensity of precipitation fluctuations (Sun et al. 2020). In the east and central parts of the study region, the climate is controlled alternately by East Asian monsoon and South Asian monsoon; no apparent change in precipitation was found in either this study or in literature (Zhang et al. 2017).

At the regional scale, the rate of changes in both temperature and precipitation were predominantly affected by elevation and vegetation cover. The NDVI declined from the east to the west of southwestern China (Fig. 5), and had highly significant $(P<0.01)$ negative correlations with changes in both annual average temperature and annual precipitation. This suggested that areas with lower vegetation covers tended to become warmer and wetter, whereas the areas associated with higher vegetation covers maintained more or less stable climatic conditions, which highlights the importance of vegetation cover in moderating climate changes (Lee et al. 2011; Peng et al. 2014; Bright et al. 2017; Li et al. 2020c). The western parts of southwestern China had relatively low NDVI with mostly the vegetation types of alpine meadow and steppe, and are at higher elevations, hence observations of a greater change in temperature (Rotenberg and Yakir 2010; Peng et al. 2014; Huang et al. 2020). The eastern parts are characterized by dense forests and scrubs and lower elevations, which are general conditions favoring temperature stability (Bonan 2008; Chao and Sun 2009; Zeng et al. 2017).

Several studies have illustrated that regions at higher elevations are more susceptible to climate changes compared with those at lower elevations (Pepin et al. 2015, 2019; Yao et al. 2016; Li et al. 2020a, 2020b; You et al. 2020). The 
Table 2 Summary of variance fractions in precipitation changes explainable by selective vegetation and topographic variables for different categories of climate change type

\begin{tabular}{|c|c|c|c|c|c|}
\hline Factor type & Variable & Regional average & $\mathrm{T}^{+} \mathrm{P}^{+}$ & $\mathrm{T}^{+}$ & NSC \\
\hline \multirow[t]{5}{*}{ Vegetation } & Vegetation type (quadratic) & $0.32^{\mathrm{NS}}$ & $1.13^{\mathrm{NS}}$ & $2.46^{\mathrm{NS}}$ & $0.85^{\mathrm{NS}}$ \\
\hline & Vegetation type (linear) & $0.32^{\mathrm{NS}}$ & $12.9 * *$ & $4.14^{*}$ & $4.78^{* *}$ \\
\hline & NDVI (quadratic) & $0.34^{\mathrm{NS}}$ & $0.45^{\mathrm{NS}}$ & $8.85 * *$ & $4.38 * *$ \\
\hline & NDVI (linear) & $12.3^{* *}$ & $2.18^{\mathrm{NS}}$ & $5.82^{\mathrm{NS}}$ & $2.32^{\mathrm{NS}}$ \\
\hline & Subtotal & 13.3 & 16.7 & 21.3 & 12.3 \\
\hline \multirow[t]{9}{*}{ Topography } & Aspect (quadratic) & $1.96^{* *}$ & $0.38^{\mathrm{NS}}$ & $0.83^{\mathrm{NS}}$ & $0.86^{\mathrm{NS}}$ \\
\hline & Aspect (linear) & $0.17^{\mathrm{NS}}$ & $4.10^{\mathrm{NS}}$ & - & - \\
\hline & Relief amplitude (quadratic) & $5.77 * *$ & $0.11^{\mathrm{NS}}$ & $4.80 * *$ & $2.51 *$ \\
\hline & Relief amplitude (linear) & $5.02 * *$ & $23.9 * *$ & $7.45^{* *}$ & $17.2 * *$ \\
\hline & Slope (quadratic) & $1.29 *$ & $3.95^{*}$ & $0.65^{\mathrm{NS}}$ & $0.04^{\mathrm{NS}}$ \\
\hline & Slope (linear) & 0.76 & $6.62^{\mathrm{NS}}$ & $0.52^{\mathrm{NS}}$ & $3.30^{\mathrm{NS}}$ \\
\hline & Elevation (quadratic) & $17.3 * *$ & $6.02 * *$ & $7.47 *$ & $31.4 * *$ \\
\hline & Elevation (linear) & $28.4 * *$ & $7.64 *$ & $39.2 * *$ & $3.82^{\mathrm{NS}}$ \\
\hline & Subtotal & 60.6 & 52.7 & 60.9 & 59.2 \\
\hline \multirow[t]{9}{*}{ Interactions } & NDVI elevation & $15.3 * *$ & $18.4 * *$ & $10.3 *$ & $7.16^{* *}$ \\
\hline & NDVI slope & $0.05^{\mathrm{NS}}$ & $0.14^{\mathrm{NS}}$ & - & $4.59 *$ \\
\hline & NDVI relief amplitude & $4.89 * *$ & $7.64 * *$ & $4.52 * *$ & $4.22 *$ \\
\hline & NDVI aspect & $0.17^{\mathrm{NS}}$ & $0.05^{\mathrm{NS}}$ & - & - \\
\hline & Vegetation type aspect & $1.38 *$ & $0.07^{\mathrm{NS}}$ & - & - \\
\hline & Vegetation type slope & $1.63^{*}$ & $0.04^{\mathrm{NS}}$ & $2.48^{\mathrm{NS}}$ & $0.37^{\mathrm{NS}}$ \\
\hline & Vegetation type relief amplitude & - & - & $0.51^{\mathrm{NS}}$ & $7.16^{* *}$ \\
\hline & Vegetation type Elevation & $0.69^{\mathrm{NS}}$ & $4.34^{\mathrm{NS}}$ & $0.02^{\mathrm{NS}}$ & $5.01 *$ \\
\hline & Subtotal & 24.1 & 30.7 & 17.8 & 28.5 \\
\hline Adj $r^{2}$ & $53.0 * *$ & $18.8^{* *}$ & $44.3 * *$ & $55.8 * *$ & \\
\hline
\end{tabular}

*Significant at $P<0.05 ; * *$ significant at $P<0.01$; ${ }^{\text {NS }}$ not significant

The missing values are due to insignificant contributions of the respective factors. Classification of climate change types: $\mathrm{T}^{+}$, warmer; $\mathrm{P}^{-}$, drier; $\mathrm{T}^{+} \mathrm{P}^{-}$, warmer-drier; $\mathrm{T}^{+} \mathrm{P}^{+}$, warmer-wetter; $\mathrm{NSC}$, no significant change

Table 3 Pearson's correlation coefficients of changes in annual average temperature $(\Delta T \mathrm{a})$ and annual precipitation $(\Delta P r)$ with selective topographic and vegetation variables by climate change types

\begin{tabular}{llcccccc}
\hline Climate variable & Climate change type & Elevation & Aspect & Slope & Relief amplitude & Vegetation type & NDVI \\
\hline$\Delta \mathrm{Ta}$ & Regional average & $0.678^{* *}$ & $0.013^{\mathrm{NS}}$ & $-0.166^{* *}$ & $-0.197^{* *}$ & $0.047^{* *}$ & $-0.720^{* *}$ \\
& $\mathrm{~T}^{+} \mathrm{P}^{-}$ & $-0.590^{* *}$ & $-0.293^{*}$ & $-0.235^{\mathrm{NS}}$ & $-0.448^{* *}$ & $-0.051^{\mathrm{NS}}$ & $0.658^{* *}$ \\
& $\mathrm{~T}^{+} \mathrm{P}^{+}$ & $0.496^{* *}$ & $0.114^{* *}$ & $-0.084^{*}$ & $-0.054^{\mathrm{NS}}$ & $-0.463^{* *}$ & $-0.728^{* *}$ \\
& $\mathrm{~T}^{+}$ & $0.521^{* *}$ & $-0.001^{\mathrm{NS}}$ & $-0.131^{* *}$ & $-0.203^{* *}$ & $0.063^{*}$ & $-0.567^{* *}$ \\
& $\mathrm{P}^{-}$ & $0.441^{* *}$ & $0.106^{\mathrm{NS}}$ & $-0.137^{\mathrm{NS}}$ & $-0.110^{\mathrm{NS}}$ & $0.142^{\mathrm{NS}}$ & $-0.244^{*}$ \\
& $\mathrm{NSC}$ & $0.071^{\mathrm{NS}}$ & $0.027^{\mathrm{NS}}$ & $-0.029^{\mathrm{NS}}$ & $-0.023^{\mathrm{NS}}$ & $0.282^{* *}$ & $-0.249^{* *}$ \\
& $\mathrm{Negional} \mathrm{average}$ & $0.685^{* *}$ & $0.008^{\mathrm{NS}}$ & $-0.117^{* *}$ & $-0.166^{* *}$ & $0.091^{* *}$ & $-0.642^{* *}$ \\
& $\mathrm{~T}^{+} \mathrm{P}^{-}$ & $0.689^{* *}$ & $0.077^{\mathrm{NS}}$ & $0.322^{*}$ & $0.310^{*}$ & $0.233^{\mathrm{NS}}$ & $-0.739^{* *}$ \\
& $\mathrm{~T}^{+} \mathrm{P}^{+}$ & $0.022^{\mathrm{NS}}$ & $0.088^{*}$ & $0.153^{* *}$ & $0.249^{* *}$ & $-0.143^{* *}$ & $-0.176^{* *}$ \\
& $\mathrm{~T}^{+}$ & $0.572^{* *}$ & $0.001^{\mathrm{NS}}$ & $-0.073^{* *}$ & $-0.174^{* *}$ & $0.128^{* *}$ & $-0.517^{* *}$ \\
& $\mathrm{P}^{-}$ & $-0.081^{\mathrm{NS}}$ & $0.017^{\mathrm{NS}}$ & $0.024^{\mathrm{NS}}$ & $0.184^{\mathrm{NS}}$ & $-0.132^{\mathrm{NS}}$ & $0.210^{\mathrm{NS}}$ \\
& $\mathrm{NSC}$ & $0.595^{* *}$ & $0.001^{\mathrm{NS}}$ & $0.286^{* *}$ & $0.342^{* *}$ & $-0.158^{* *}$ & $-0.352^{* *}$ \\
\hline
\end{tabular}

*Significant at $P<0.05 ; * *$ significant at $P<0.01 ;{ }^{\text {NS }}$ no significant change

Classification of climate change types: $\mathrm{T}^{+}$, warmer; $\mathrm{P}^{-}$, drier; $\mathrm{T}^{+} \mathrm{P}^{-}$, warmer-drier; $\mathrm{T}^{+} \mathrm{P}^{+}$, warmer-wetter; NSC, no significant change 
study of Li et al. (2020c) found that in regions with low rainfall, increases in elevation intensify the warming potential. This is further confirmed in our study: with declining MAP from the southeast to the northwest of the study region, the rate of changes in temperature trended higher; the rate of changes in temperature was positively correlated with elevation. Similar findings have been widely reported (Fan et al. 2011; Arakawa and Kitoh 2012; Li et al. 2017; Minder et al. 2018; Aguilar-Lome et al. 2019).

Within our study region, several contrasting climate change types were identified, and they were affected differentially by topography and vegetation. In areas with climate change types of warming and drying, warming and humidification, and no significant changes, vegetation cover contributed most to the temperature variability. The responses of temperature changes to NDVI conformed to the general pattern found at the regional scale. In areas with climate change type of drying, temperature changes were predominantly affected by topography, in particular the elevation. The areas of typically warming were affected interactivey by topography and vegetation in temperature variability. Precipitation changes were predominantly affected by topographic factors such as relief amplitude and elevation.

Overall, the southwestern China experienced intensified temperature increases from the east and southeast to the west and northwest, suggesting intensified influences of the southeasterly monsoon and the southerly monsoon, while the westerly alpine influences subsided; topography and vegetation affected the magnitudes of the directional changes in climate at a local scale.

Open Access This article is licensed under a Creative Commons Attribution 4.0 International License, which permits use, sharing, adaptation, distribution and reproduction in any medium or format, as long as you give appropriate credit to the original author(s) and the source, provide a link to the Creative Commons licence, and indicate if changes were made. The images or other third party material in this article are included in the article's Creative Commons licence, unless indicated otherwise in a credit line to the material. If material is not included in the article's Creative Commons licence and your intended use is not permitted by statutory regulation or exceeds the permitted use, you will need to obtain permission directly from the copyright holder. To view a copy of this licence, visit http://creativecommons.org/licenses/by/4.0/.

\section{References}

Aguilar-Lome J, Espinoza-Villar R, Espinoza JC, Rojas-Acuña J, Willems BL, Leyva-Molina WM (2019) Elevation-dependent warming of land surface temperatures in the andes assessed using MODIS LST time series (2000-2017). Int J Appl Earth Obs 77:119-128

Arakawa O, Kitoh A (2012) Elevation dependency of summertime precipitation and its change by global warming over the tibetan plateau and the surroundings simulated by a $60-\mathrm{km}-\mathrm{mesh}$ atmospheric general circulation model. J Meteorol Soc Jpn 90A:151-165

Barros AP, Chiao S, Lang TJ, Burbank DW, Putkonen J (2006) From weather to climate-seasonal and interannual variability of storms and implications for erosion processes in the Himalaya. Geol Soc Amer Spec Pap 398:17-38

Bonan GB (2008) Forests and climate change: forcings, feedbacks, and the climate benefits of forests. Science 320:1444-1449

Bright RM, Davin E, O'Halloran T, Pongratz J, Zhao KG, Cescatti A (2017) Local temperature response to land cover and management change driven by non-radiative processes. Nat Clim Chang 7:296-302

Bromley GT, Gerken T, Prein AF, Stoy PC (2020) Recent trends in the near-surface climatology of the Northern North American great plains. J Climate 33:461-475

Buermann WG, Forkel M, O'Sullivan M, Sitch S, Friedlingstein P, Haverd V et al (2018) Widespread seasonal compensation effects of spring warming on northern plant productivity. Nature 562:110-115

Cai Y, Li DL, Tang MC, Bai CY (2003) Decadal temperature changes over Qinghai-Xizang plateau in recent 50 years. Plateau Meteorol 22:464-470 (in Chinese with English abstract)

Chao LM, Sun JX (2009) Temporal change in annual air temperature and heat island effect in a coastal city at mid-latitude in China during 1956-1998. Chin J Appl Ecol 20:2839-2846 (in Chinese with English abstract)

Chen DL, Xu BQ, Yao SD, Guo ZT, Cui P, Chen FH et al (2015) Assessment of past, present and future environmental changes on the tibetan plateau. Chin Sci Bull 60:3025-3035 (in Chinese with English abstract)

China Meteorological Administration (2020) Blue Book on Climate Change in China 2020. Science Press, Beijing

Duan JP, Li L, Chen L, Zhang HX (2020) Time-dependent warming amplification over the tibetan plateau during the past few decades. Atmos Sci Lett 21:e998

Fan ZX, Bräuning A, Thomas A, Li JB, Cao KF (2011) Spatial and temporal temperature trends on the yunnan plateau (Southwest China) during 1961-2004. Int J Climatol 31:2078-2090

Gross N, Le Bagousse-Pinquet Y, Liancourt P, Berdugo M, Gotelli NJ, Maestre FT (2017) Functional trait diversity maximizes ecosystem multifunctionality. Nat Ecol Evol 1:0132

Harris I, Osborn TJ, Jones P, Lister D (2020) Version 4 of the CRU TS monthly high-resolution gridded multivariate climate dataset. Sci Data 7:109

He JL, Zhao W, Li AN, Wen FP, Yu DJ (2019) The impact of the terrain effect on land surface temperature variation based on landsat- 8 observations in mountainous areas. Int J Remote Sens 40:1808-1827

Huang B, Hu XP, Fuglstad GA, Zhou X, Zhao WW, Cherubini F (2020) Predominant regional biophysical cooling from recent land cover changes in Europe. Nat Commun 11:1066

Intergovernmental Panel on Climate Change (IPCC) (2013) Climate change 2013: the physical science basis: summary for policymakers. Cambridge University Press, Cambridge, pp 1-30

Jiang QF (2003) Moist dynamics and orographic precipitation. Tellus A 55:301-316

Kang SC, Xu YW, You QL, Flugel WA, Pepin N, Yao TD (2010) Review of climate and cryospheric change in the tibetan plateau. Environ Res Lett 5:015101

Knott GD (2012) Interpolating cubic splines. Springer Science \& Business Media, Berlin

Lee X, Goulden ML, Hollinger DY, Barr A, Black TA, Bohrer G et al (2011) Observed increase in local cooling effect of deforestation at higher latitudes. Nature 479:384-387

Li BF, Chen YN, Shi X (2020a) Does elevation dependent warming exist in high mountain Asia? Environ Res Lett 15:024012 
Li CX, Wang CZ, Zhao TB (2020b) Seasonal covariability of dryness or wetness in China and global sea surface temperature. J Climate 33:727-747

Li L, Chen XG, Wang ZY, Xu WX, Tang HY (2010) Climate change and its regional differences over the tibetan plateau. Adv Clim Change Res 6:181-186 (in Chinese with English abstract)

Li L, Zha Y, Zhang JH, Li YM, Lyu H (2020c) Effect of terrestrial vegetation growth on climate change in China. J Environ Manage 262:110321

Li QF, Yang GJ (2017) Temporal distribution characteristics of alpine precipitation and their vertical differentiation: a case study from the upper Shule River. Water 9:284

Li XP, Wang L, Guo XY, Chen DL (2017) Does summer precipitation trend over and around the tibetan plateau depend on elevation? Int J Climatol 37:1278-1284

Liu X, Chen B (2000) Climatic warming in the tibetan plateau during recent decades. Int J Climatol 20:1729-1742

Liu XD, Cheng ZG, Yan LB, Yin ZY (2009) Elevation dependency of recent and future minimum surface air temperature trends in the Tibetan Plateau and its surroundings. Glob Planet Change 68:164-174

Minder JR, Letcher TW, Liu CH (2018) The character and causes of elevation-dependent warming in high-resolution simulations of Rocky Mountain climate change. J Climate 31:2093-2113

Peng SS, Piao SL, Zeng ZZ, Ciais P, Zhou LM, Li LZX et al (2014) Afforestation in China cools local land surface temperature. Proc Natl Acad Sci U S A 111:2915-2919

Pepin N, Bradley RS, Diaz HF, Baraer M, Caceres EB, Forsythe $\mathrm{N}$ et al (2015) Elevation-dependent warming in mountain regions of the world. Nat Clim Change 5:424-430

Pepin N, Deng HJ, Zhang HB, Zhang F, Kang SC, Yao TD (2019) An examination of temperature trends at high elevations across the Tibetan Plateau: the use of MODIS LST to understand patterns of elevation-dependent warming. J Geophys Res 124:5738-5756

Piao SL, Ciais P, Huang Y, Shen ZH, Peng SS, Li JS et al (2010) The impacts of climate change on water resources and agriculture in China. Nature 467:43-51

R Development Core team (2018) A language and environment for statistical computing. R Found Stat Comput, Vienna

Rotenberg E, Yakir D (2010) Contribution of semi-arid forests to the climate system. Science 327:451-454

Ruffin C, King RL, Younan NH (2008) A combined derivative spectroscopy and savitzky-golay filtering method for the analysis of hyperspectral data. Gisci Remote Sens 45:1-15

Shen MG, Piao SL, Jeong SJ, Zhou LM, Zeng ZZ, Ciais P et al (2015) Evapourative cooling over the Tibetan Plateau induced by vegetation growth. Proc Natl Acad Sci U S A 112:9299-9304
Sun J, Yang K, Guo WD, Wang Y, He J, Lu H (2020) Why has the inner tibetan plateau become wetter since the mid-1990s? J Clim 33:8507-8522

Tan XZ, Wu Y, Gomez N, Liu BJ, Chen SL (2020) Inconsistent changes in global precipitation seasonality in seven precipitation datasets. Clim Dynam 54:3091-3108

The Editorial Committee of Vegetation Map of China (2007) Vegetation map of the People's Republic of China (1:1000000). Geological Publishing House, Beijing

Wang SP, Wang ZH, Piao SL, Fang JY (2010) Regional differences in the timing of recent air warming during the past four decades in China. Chin Sci Bull 55:1968-1973

Yang K, Ye BS, Zhou DG, Wu BY, Foken T, Qin J, Zhou ZY (2011) Response of hydrological cycle to recent climate changes in the tibetan plateau. Clim Change 109:517-534

Yang M, Zhang W (2019) Orographic effects of geomorphology on precipitation in a pluvial basin of the eastern tibetan plateau. Water 11:250

Yao JQ, Yang Q, Mao WY, Zhao Y, Xu XB (2016) Precipitation trendelevation relationship in arid regions of the China. Glob Planet Change 143:1-9

Yin LC, Wang XF, Feng XM, Fu BJ, Chen YZ (2020) A comparison of SSEBop-model-based evapotranspiration with eight evapotranspiration products in the yellow river basin. China Remote Sens 12:2528

You QL, Chen DL, Wu FY, Pepin N, Cai ZY, Ahrens B, Jiang ZH, Wu ZW, Kang SC, AghaKouchak A (2020) Elevation dependent warming over the tibetan plateau: patterns, mechanisms and perspectives. Earth-Sci Rev 210:103349

Zeng ZZ, Piao SL, Li LZX, Zhou LM, Ciais P, Wang T et al (2017) Climate mitigation from vegetation biophysical feedbacks during the past three decades. Nat Clim Change 7:432-436

Zhang C, Tang QH, Chen DL, Li LF, Liu XC, Cui HJ (2017) Tracing changes in atmospheric moisture supply to the drying Southwest China. Atmos Chem Phys 17:10383-10393

Zhao CF, Yang YK, Fan H, Huang JP, Fu YF, Zhang XY et al (2020) Aerosol characteristics and impacts on weather and climate over the tibetan plateau. Natl Sci Rev 7:492-495

Zheng D (2008) The systematic research of Chinese eco-geographical areas. Commercial Press, Beijing

Publisher's Note Springer Nature remains neutral with regard to jurisdictional claims in published maps and institutional affiliations. 